LA INVENCIÓN DEL PATRIMONIO NATURAL EN ESPAÑA. POLÍTICA, ACADEMIA, ACTIVISMO Y COMUNICACIÓN /

THE INVENTION OF NATURAL HERITAGE IN SPAIN. POLITICS, ACADEMY, ACTIVISM AND COMMUNICATION

\section{PATRIAS PRIMITIVAS. DISCURSOS E IMÁGENES DE LA NATURALEZA EN EL PRIMER CONSERVACIONISMO ESPAÑOL}

\author{
Santos Casado \\ Universidad Autónoma de Madrid \\ santos.casado@uam.es
}

\section{PRIMITIVE FATHERLANDS. NATURE DISCOURSES AND IMAGES FROM THE FIRST SPANISH CONSERVATIONISM}

Cómo citar este artículo/Citation: Casado, S. (2016). Patrias primitivas. Discursos e imágenes de la naturaleza en el primer conservacionismo español. Arbor, 192 (781): a343. doi: http:// dx.doi.org/10.3989/arbor.2016.781n5001
Copyright: (c) 2016 CSIC. Este es un artículo de acceso abierto distribuido bajo los términos de la licencia Creative Commons Attribution (CC BY) España 3.0.
RESUMEN: Los orígenes de los Parques Nacionales y otras reservas proporcionan una oportunidad historiográfica para investigar diversos procesos científicos, culturales y sociales en la España de principios del XX. Por un lado, en España la conservación, al igual que en otros países occidentales, se originó en estrecha relación con las típicas preocupaciones finiseculares en torno a decadencias sociales y nacionales, especialmente en cuanto a las amenazas derivadas de la industrialización y la urbanización. Por otro lado, si bien el clima regeneracionista propiciaba un amplio movimiento de signo reformista y modernizador, también se trataba de recuperar y fortalecer una maltrecha identidad nacional. Así, la creación y los primeros pasos de los Parques y otras iniciativas conservacionistas estuvieron muy ligados al desarrollo de discursos ideológicos e imágenes culturales en torno a los Parques, los paisajes y la fauna salvaje de España, entendidos como poderosos reservorios de virtudes cívicas y de símbolos para la identidad nacional.

PALABRAS CLAVE: Parques Nacionales; historia de la conservación; historia de España; Pedro Pidal; Museo Nacional de Ciencias Naturales (Madrid); historia de la taxidermia.
ABSTRACT: The origins of National Parks and other protected areas provide a historiographical window to investigate scientific, cultural, and ideological processes in early-twentiethcentury Spain. On the one hand, nature conservation, in Spain as in other Western countries, was intimately related to turnof-the-century concerns about national and social decadence, especially with regard to the perceived threats posed by industrialization and urbanization processes. On the other hand, while the ideological climate of Spanish regeneracionismo supported a broad movement of modernization and reform, ways to reinvigorate national identity were also sought. Therefore the establishment and first stages of National Parks, Nature Reserves and other conservation schemes were closely linked to the development of ideological discourses and cultural images around Spanish Parks, landscapes, and fauna, seen as powerful repositories of civic virtues and national symbols.

KEYWORDS: National parks; history of conservation; history of Spain; Pedro Pidal; Museo Nacional de Ciencias Naturales (Madrid); history of taxidermy. 
La civilización urbana del siglo XIX condujo en Occidente, por vía de reacción compensatoria, a una nueva valoración apreciativa del campo, de la montaña y, en general, de todas las manifestaciones de la naturaleza que pudieran interpretarse como antagónicas o complementarias, según los puntos de vista, de los males de la ciudad. La vieja comparación moral entre campo y ciudad, utilizada y reutilizada durante siglos más como artificio literario que como genuina crítica transformadora, se recupera ahora, finales del XIX y principios del XX, como significativa expresión de malestar colectivo. Un malestar específicamente urbano, aunque mezclado, eso sí, con la variada y a veces confusa gama de desasosiegos morales, culturales y políticos que recorren el cambio de siglo.

Frente al desarraigo, el descreimiento y la anomia moral de la "anémica vida ultra-urbana", según la significativa caracterización que de su propio tiempo hiciera el pedagogo y filósofo español Francisco Giner, se oponen las capacidades regeneradoras del contacto con lo rural y lo natural (Giner de los Ríos, 1886, p. 104). Regeneración para los individuos, para los ciudadanos, pero también para la colectividad, para la vida nacional en su conjunto. Porque, siguiendo la tradición romántica, allí, en los campos y en las montañas, debía de encontrarse también la esencia del pueblo y de la nación. De ahí que, en España como en otros lugares, los movimientos de exaltación de la naturaleza combinaran a menudo regeneracionismo y nacionalismo (Casado, 2010). Y quizá sea en el excursionismo catalán y catalanista de entre siglos donde mejor se aprecie, en el ámbito hispano, esta triple conexión. Una de las manifestaciones más concentradas que he hallado de este ideario de regeneración patriótica a través del contacto ciudadano con la naturaleza se encuentra en las palabras, transcritas según la grafía aún vacilante de la época, de uno de los ponentes del Primer Congrés Excursionista Catalá, celebrado en Lérida en 1911.

"Lo «Centre Excursionista» té per fi primordial la cultura catalana, refer la Patria [...] En aqueixa feyna hi caben desde 'I turisme, desde l' esbarjo sá y laudable, de brasset ab l' higiene, que sustreu a ciutat una colla de socis y 'Is porta a trescar per la montanya, a corre 'I Pirineu, a recrear noblement l' esperit ab visions incomparables de paissatges [...], fins al geólech que examina les capes de la terra, fins al entomólech que atrapa 'I diminut insecte, fins al folk-lorista qui sotja pacientment l' ánima del nostre poble, que 's transparenta en ses cansons populars" (Esteve, 1911, p. 252).
La tarea de "rehacer la Patria" requería así recorrer sus más apartados rincones en una búsqueda arqueológica de su sustrato físico y moral, tal como hacen el "geólogo que examina las capas de la Tierra" o el "folclorista que escudriña pacientemente el alma de nuestro pueblo". Pero también construir una nueva ciudadanía, fortalecida en cuerpo y espíritu a través del "esparcimiento sano" e higiénico y del recreo ennoblecedor que se hallan en el frecuentamiento de la naturaleza y en el disfrute de las "visiones incomparables" de sus paisajes.

\section{PARQUES NACIONALES, COMO SU NOMBRE INDICA}

Que para recuperar y reforzar sentimientos de pertenencia y de identidad colectivas podía recurrirse a la naturaleza y al "apego al lugar" frente a los "desplazamientos de la modernidad" (Lekan, 2004, p. 8) es algo que ya se sabía desde el romanticismo y que, en la práctica, se había venido ensayando durante el último tercio del XIX, tanto para dotar de nuevos mitos y símbolos a naciones jóvenes y emergentes, caso de los Parques Nacionales en los Estados Unidos (Shaffer, 2001), como para intentar recuperar reliquias con que fortalecer identidades nacionales debilitadas o atribuladas, caso del Heimatschutz o movimiento para proteger la cultura y los paisajes locales en Alemania (Williams, 1996). Y la misma lógica se halla, al comenzar el siglo XX, en las primeras propuestas formuladas en España para reunir nuevamente, también aquí, naturaleza y nación bajo la figura del Parque Nacional.

El ingeniero de montes catalán Rafael Puig y Valls había conocido de cerca la experiencia norteamericana durante su viaje a la World's Columbian Exposition, celebrada en Chicago en 1893 (Casals Costa, 1994; Boada, 1995). En 1902, con motivo de la Fiesta del Árbol convocada en Barcelona, Puig y Valls lanza la primera propuesta formal para la creación en España de un "Parque Nacional", que, de acuerdo a su visión, debía establecerse en Montserrat. La conjunción de paisaje, patriotismo y religión, allí disponible para los ciudadanos de una Cataluña crecientemente urbanizada, hacía del proyectado "Parque Nacional de la Montaña de Montserrat" un "centro regenerador de vida, de aire puro, de algo que extinga la sed que todos padecemos de admirar, en los monumentos de la Patria, lo que es y lo que debe ser, bien cultivado, patrimonio nacional". El futuro Parque sería "un ideal para el devoto, una maravilla para el naturalista, un prodigio para el creyente y un monumento para el patriota" (Discurso leído por D. Rafael Puig y Valls, pp. 45-46). 
La propuesta de Puig y Valls no prosperó en aquel momento. Tampoco los llamamientos formulados desde los sucesivos congresos del excursionismo catalán (Solé i Massip y Bretón Solo de Zaldívar, 1986, p. 26), a los que antes se ha aludido. Pero cuando en 1916 Pedro Pidal, vástago de una importante dinastía política asturiana de signo netamente conservador, planteó de nuevo la cuestión, esta vez en sede parlamentaria, la referencia al modelo estadounidense y la retórica nacionalista reaparecieron puntualmente. Lo cual, por cierto, suscitaba una vez más la ambivalencia emocional que, desde el 98, producía la referencia a Estados Unidos en el nacionalismo español, a la vez humillado y admirativamente espoleado por el poderío norteamericano. En su defensa ante el Senado de la propuesta de Ley de Parques Nacionales, Pidal recurría precisamente a esta posible contradicción entre lo hispánico y lo anglosajón para tratar de movilizar en su favor el orgullo patrio.

\footnotetext{
"Y cuando en la actual Exposición Universal de San Francisco de California llegué á contemplar en el hermoso pabellón de la República Argentina el panorama de las cataratas del Iguazú con el gran letrero que ponía: «Las mayores del mundo», yo, que venía de visitar el Niágara, el Yellowstone y el Yosemite, sentí hervir la sangre de la raza, y tuve que contenerme lo bastante para no alterar el religioso silencio de los que contemplaban el panorama con el grito natural y espontáneo de iViva la República Argentina!" (Discurso del Sr. Marqués de Villaviciosa de Asturias, pp. 358-359).
}

El recurso retórico debió de funcionar, pues la trascripción del discurso incluye, inmediatamente a continuación, uno de esos "Muy bien" con los que el Diario de las Sesiones de Cortes recoge las sonoras muestras colectivas de asentimiento y aplauso que sus señorías se otorgan mutuamente. Pero el valor simbólico de los Parques Nacionales no solo había de funcionar hacia el exterior sino, sobre todo, hacia el interior, como aportación a la imagen colectiva de la nación y de la relación de esta con su territorio. Y, de puertas adentro, las virtudes que los Parques Nacionales prometían para esa movilización nacionalista planteaban, nuevamente, posibles contradicciones, en este caso entre diversos nacionalismos, de signo centrípeto y centrífugo, en competencia. A este respecto, Pidal quiso reconocer la prioridad de Cataluña en cuanto a las iniciativas conservacionistas, pero tratando de desmontar, al mismo tiempo, su vinculación con el catalanismo político. Así, en el mismo discurso, Pidal declara su admiración por los catalanes y felicita a quienes desde Cataluña habían lanzado previas pro- puestas para crear allí Parques Nacionales. Pero, añade, "antes que los Parques Nacionales de Cataluña, que al ser de una región ya no podrían llamarse «Nacionales», y esto es evidente, debemos todos crear Ios PARques NACIONALES DE ESPAÑA", los cuales lo "serán también de Cataluña y de Andalucía, de Galicia y de Murcia, de Baleares y de Canarias, sea cual fuere el punto del territorio nacional, peninsular ó extrapeninsular, en que radiquen" (Discurso del Sr. Marqués de Villaviciosa de Asturias, p. 360).

Sea como fuere, la propuesta de Pidal fue finalmente aprobada, de modo que desde 1916 España contó con una Ley de Parques Nacionales. La ocasión de aplicarla de modo efectivo se presentó poco después, en 1918, con ocasión del duodécimo centenario de la batalla de Covadonga (Boyd, 2002). Es interesante anotar, en relación con el análisis de la dimensión nacionalista del primer conservacionismo español que aquí se está abordando, que esa primera declaración de un Parque Nacional en España, que fue la del Parque Nacional de la Montaña de Covadonga, no se efectuó mediante una ley específica sino que vino incrustada en la más amplia Ley de 22 de julio de 1918 por la que se aprobaba el programa oficial de la conmemoración de la citada efeméride. En ella se preveían diversas iniciativas de exaltación patriótica, moduladas bajo el ideario regeneracionista del momento. Se disponía la creación en Asturias de una nueva escuela industrial "adaptada preferentemente á las mayores actividades económicas de aquella región", se convocaba un premio para estudios históricos y literarios sobre la reconquista, se promovían las obras pendientes para acondicionar en Covadonga el entorno de la cueva santa y, en lo que aquí importa, se establecía en el corazón de los Picos de Europa, en torno del milagroso escenario de la batalla que fuera mítica cuna de la nación española, un Parque Nacional (Ley [de] veintidós de Julio de mil novecientos dieciocho).

Precisamente porque la densidad de referencias históricas, religiosas y, en definitiva, ideológicas, es tan excesiva en el caso de Covadonga, puede resultar interesante examinar el caso del segundo Parque Nacional creado en 1918, apenas un mes después del primero, en un contexto aparentemente menos cargado de connotaciones nacionalistas y, por tanto, de mayor sobriedad cultural en el aprecio de los valores estrictamente derivados de la naturaleza y el paisaje. Se trata del Parque Nacional del Valle de Ordesa, en el Pirineo oscense, declarado como tal por un Real Decreto de fecha 16 de agosto de 1918. 
Figura 1. Discurso de Francesc Cambó en presencia de los reyes en el acto de inauguración del Parque Nacional de Covadonga, 8 de septiembre de 1918

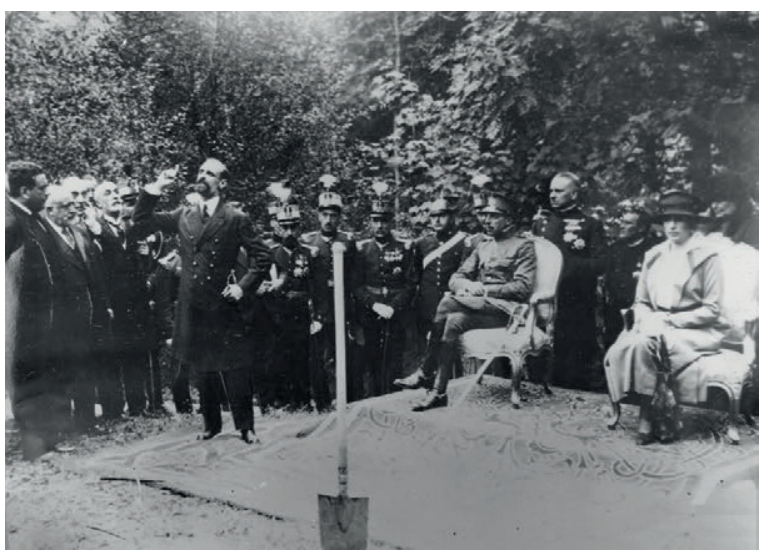

Cortesía de la Asociación Cultural Abamia de Corao (Cangas de Onís, Asturias)

En una primera aproximación, saltan a la vista los sobresalientes méritos paisajísticos de este majestuoso escenario de montaña, que desde hacía tiempo habían descubierto y ensalzado los alpinistas, o mejor pirineístas, españoles y sobre todo franceses (Martínez de Pisón, 2000), y que lo hacían acreedor al alto reconocimiento implícito en la designación de Parque Nacional. Pero, examinado el caso en mayor detalle, resulta que, a más de sus insuperables atributos estéticos, Ordesa podía ofrecer, al igual que Covadonga, lecturas morales y patrióticas derivadas de la tradición y la historia. Este ciclópeo paisaje montañoso aparecía, en la leyenda, ligado a las míticas gestas de Roldán y, a la luz de la historia, podía considerarse también parte del reducto originario de la reconquista cristiana, correspondiente en este caso a su núcleo pirenaico y aragonés.

Pero no hace falta suponer esta posible lectura nacionalizadora de Ordesa. En el preámbulo expositivo del mencionado Decreto por el que se creaba el nuevo Parque se hacía explícita la idea de que en estos lugares "los montes y los valles conservan el aspecto peculiar de la Patria, en su primitivo estado natural, integrando los recuerdos de sus orígenes, siendo el vivo testigo de sus tradiciones" (Real Decreto [de] dieciséis de Agosto de mil novecientos dieciocho, p. 493). Los Parques Nacionales podían funcionar así a modo de patrias primitivas, en las que revigorizar sentimientos, identidades e ideales colectivos, aprovechando su benéfico influjo para lo que en la época se veía como higienización física y moral de la ciudadanía. $\mathrm{O}$, dicho de nuevo en las palabras del Decreto, "para fomentar ese movimiento de inclinación al campo, tan conveniente para la vigorización de la raza, por la mejora de las costumbres y la práctica del estudio" (Real Decreto [de] dieciséis de Agosto de mil novecientos dieciocho, p. 493).

Y, si hiciera falta abundar en el argumento, podría igualmente citarse el siguiente caso, en orden cronológico, de declaración de un espacio protegido en España, correspondiente a los alrededores del monasterio de San Juan de la Peña, también en la provincia de Huesca. Se creó en esta ocasión no un Parque sino una figura de menor rango, bajo la denominación de Sitio Nacional del Monte de San Juan de la Peña. Se conseguía así, nuevamente, una patriótica conjunción de paisaje y tradición, evocada por el legislador, como ahora se verá, al considerar este lugar como una "Covadonga aragonesa". La Real Orden de 5 de noviembre de 1920 por la que se disponía la protección responde, en efecto, al mismo esquema retórico.

“[...] el legendario monte Pano, cuna de la epopeya medioeval aragonesa, enaltecido más tarde con el nombre de San Juan de la Peña, guarda entre las bellezas naturales de atractivos paisajes, recuerdos históricos y sentimientos religiosos del más alto valor espiritual.

El pino, el haya, el pinabete y el tilo, en armoniosa mezcla con otras especies sobre un suelo de variada configuración, prestan sugestivo marco a su austero Monasterio antiguo, que perpetúa una de esas tradiciones en que la poesía y la fe exaltan la piedad del pueblo y custodia en sagrado depósito los restos de ilustres Reyes de Navarra y Aragón. [...] Con razón ha sido llamado el monte de San Juan de la Peña la Covadonga aragonesa" (Real Orden [de] 30 de Octubre de 1920).

En la creación de estos primeros espacios protegidos confluían pues varios movimientos de diverso orden político, social y cultural (Casado, 2010, pp. 221-239). A las consideraciones propias del ideario forestalista de los ingenieros de montes españoles, que habían desarrollado desde mediados del XIX todo el programa de defensa de los bosques luego cooptado por el regeneracionismo, se sumaban un renovado aprecio estético del paisaje natural, fácilmente detectable si se atiende a la pintura española de entresiglos, una generalizada inquietud sobre las consecuencias deletéreas y la insalubridad de los modos de vida urbanos, $y$, como se ha visto en los párrafos precedentes, una visión de la naturaleza patria claramente articulada en términos de regeneración social e identitaria. 
Cabe dudar, eso sí, de cuál fuera, en términos prácticos, y más allá de la inflamada retórica del momento, el alcance efectivo de estas primeras medidas de conservación de la naturaleza en cuanto a sus beneficios, o su repercusión en general, para el común de la ciudadanía.

\section{IMÁGENES DE LA NATURALEZA HISPANA}

A diferencia del excursionismo catalanista (Martí Henneberg, 1994), multiplicado en docenas de entidades y grupos locales, o del movimiento de la Fiesta del Árbol (Casals Costa, 1994), promovido inicialmente por Puig y Valls y luego extendido a ciudades y pueblos de toda España, los primeros Parques Nacionales resultaron en la práctica fenómenos más bien elitistas y de alcance social muy limitado.

De hecho, una de las preocupaciones iniciales de la Junta Central de Parques Nacionales, que fue la entidad creada para ocuparse de esta primera parcela administrativa de la conservación española, se centró en la construcción o al menos la mejora de los accesos a los Parques para que el turismo pudiera efectivamente llegar a estos selectos pero apartados rincones de la natura hispana. Así lo preveía la propia Ley de Parques Nacionales, que en su muy sucinto texto, apenas tres artículos, no olvidaba sin embargo disponer que el Ministerio de Fomento consignase "en sus presupuestos las cantidades necesarias para vías de comunicación y sostenimiento de todos ellos" (Ley sancionada por S. M. creando en España los Parques nacionales).

"El valle de Ordesa está actualmente aislado del resto de España", se advertía tras la declaración del parque, de manera que, mientras no llegasen las carreteras reclamadas por la Junta, "no puede esperarse en modo alguno que el Parque nacional y los espléndidos sitios que le rodean sean lugar de intenso turismo" (Hernández-Pacheco, 1920, pp. 276-277). Y todavía en 1930 había que insistir en que "el pueblo español tiene derecho indiscutible a poder gozar de las extraordinarias bellezas" de Ordesa, "apenas conocidas hoy de algunos alpinistas y entusiastas excursionistas" (Anónimo, 1930, p. 42). En Covadonga, y ante la inoperancia oficial, Pidal llegó a financiar de su "peculio particular" algunos kilómetros de carretera para iniciar la ruta hacia lo que consideraba una de las maravillas del Parque, el mirador de Ordiales, ruta que luego se continuó "con fondos del Presupuesto" pero que, llegados los años treinta, permanecía inacabada (Pidal, 1934, p. 5).
Pero si el frecuentamiento físico de los Parques Nacionales, en formatos turísticos más o menos elitistas o populares, se reducía probablemente a algunos centenares, o a lo sumo unos pocos miles, de personas al año, y mientras las medidas de promoción y facilitación iban teniendo efecto, cabía no obstante movilizar la conciencia y hasta el disfrute de su existencia en públicos mucho más amplios a través de las imágenes culturales que de ellos, y de otra serie de paisajes y objetos altamente simbólicos de la naturaleza hispana, se habían ido elaborando.

En el caso estadounidense, se conoce bien la importancia que para el establecimiento en 1872 del Yellowstone National Park, primer Parque Nacional del mundo, tuvieron las imágenes fotográficas y pictóricas generadas por artistas que acompañaron a las expediciones de reconocimiento de aquel prodigioso territorio. Artistas como el fotógrafo William Henry Jackson (Findley, 1989) o el pintor Thomas Moran (Kinsey, 1992), cuyas obras pronto alcanzaron una notable celebridad. A este respecto, resulta significativo que un espectacular óleo de Moran, The Grand Canyon of the Yellowstone, fuese adquirido por el Congreso estadounidense en 1872 , el mismo año en que se declaró el Parque. Los congresistas convinieron en el pago de la entonces enorme suma de diez mil dólares para colgar este potente icono de la naturaleza norteamericana de las paredes del Capitolio. Al tiempo, revistas ilustradas y reproducciones cromolitográficas se encargaban de la difusión de las imágenes de Jackson y Moran a lo largo y ancho del país.

Ciertamente no pueden establecerse relaciones tan directas en el caso español entre la producción de imágenes aptas para un amplio consumo cultural y el desarrollo de las iniciativas conservacionistas. En torno a Covadonga sí existía un previo interés en el tratamiento pictórico de sus poderosos paisajes, si bien más vinculado a la conjunción de religiosidad y tradición histórica que de modo tan intenso se asociaba a estos lugares. La combinación de los ciclópeos roquedos de los Picos de Europa con las referencias a la tradición y la devoción en torno de la cueva santa habían dado motivo, a lo largo del XIX, a lienzos románticos o realistas de pintores tan estimables como Genaro Pérez Villaamil o Martín Rico, algunas de cuyas imágenes se habían difundido también en forma de grabados en la prensa ilustrada de la época (Barón, 2012, pp. 128-130).

Ordesa no había sido especialmente descubierta por pintores o grabadores, pero sí había recibido atención desde el nuevo mundo de la fotografía, y en particu- 
lar de la fotografía de montaña, que despuntaba como naciente especialidad también en España. De hecho tanto Covadonga como Ordesa encontraron su codificación iconográfica en las primeras décadas del siglo $X X$ a través de este nuevo género fotográfico, que se difundió sobre todo a través del también nuevo formato literario de las revistas de montaña. Revistas, como las que editaban la Sociedad Peñalara o el Club Alpino Español, en las cuales, y al igual que en una incipiente producción editorial de libros especializados, se hizo pronto cláusula de estilo la abundante ilustración basada en fotografías tomadas por montañeros convertidos en fotógrafos o fotógrafos convertidos en montañeros.

El propio Pidal había completado su campaña en favor del Parque Nacional de Covadonga, en parte recogida en libros autoeditados en los que recopilaba sus discursos y artículos (Fernández, 2004), con un excepcional volumen ilustrado, titulado simplemente Picos de Europa, que realizó en colaboración con el montañero José Fernández Zabala y que fue publicado por el Club Alpino Español justo al tiempo que se creaba el nuevo Parque. Picos de Europa era sobre todo un libro ilustrado, como subraya elocuentemente la inclusión, justo después de la portada, de una relación encabezada con un "llustraciones de", en la que se consignan los autores de las docenas de fotografías y grabados que avaloran el volumen y que se recrean sobre todo en la rotundidad paisajística de los picachos, los roquedos y los desfiladeros de estas montañas (Pidal y Zabala, 1918) ${ }^{1}$. También en los volúmenes misceláneos que desde 1912 publicaba anualmente el Club Alpino, o en la revista Peñalara que al año siguiente puso en circulación la sociedad montañera del mismo nombre (Fernández, 2001), fueron apareciendo artículos y relatos ilustrados sobre los principales macizos montañosos de la Península, incluidos los escenarios que pronto iban a ser distinguidos como Parques en Covadonga y Ordesa, e igualmente otros para los que se reclamó en distintos momentos tal protección, caso de Gredos, Guadarrama o Sierra Nevada, aunque esta no llegara a concretarse entonces.

Por tomar un ejemplo entre otros muchos similares, en el Anuario publicado por el Club Alpino Español en 1929 se reproducen, apoyándose en la calidad del buen papel satinado empleado en su edición, toda una serie de paisajes del Parque Nacional de Covadonga y su entorno. Unos, llenos de vigor montañero, como la panorámica de las peñas Santas tomada por Antonio Prast. Otros, evocadores de un más plácido bucolismo, como en la vista de la basílica desde la carretera de los lagos debida al marqués de Santa María
Figura 2. Cubierta de Picos de Europa, monografía divulgativa de Pedro Pidal y José Fernández Zabala publicada en 1918

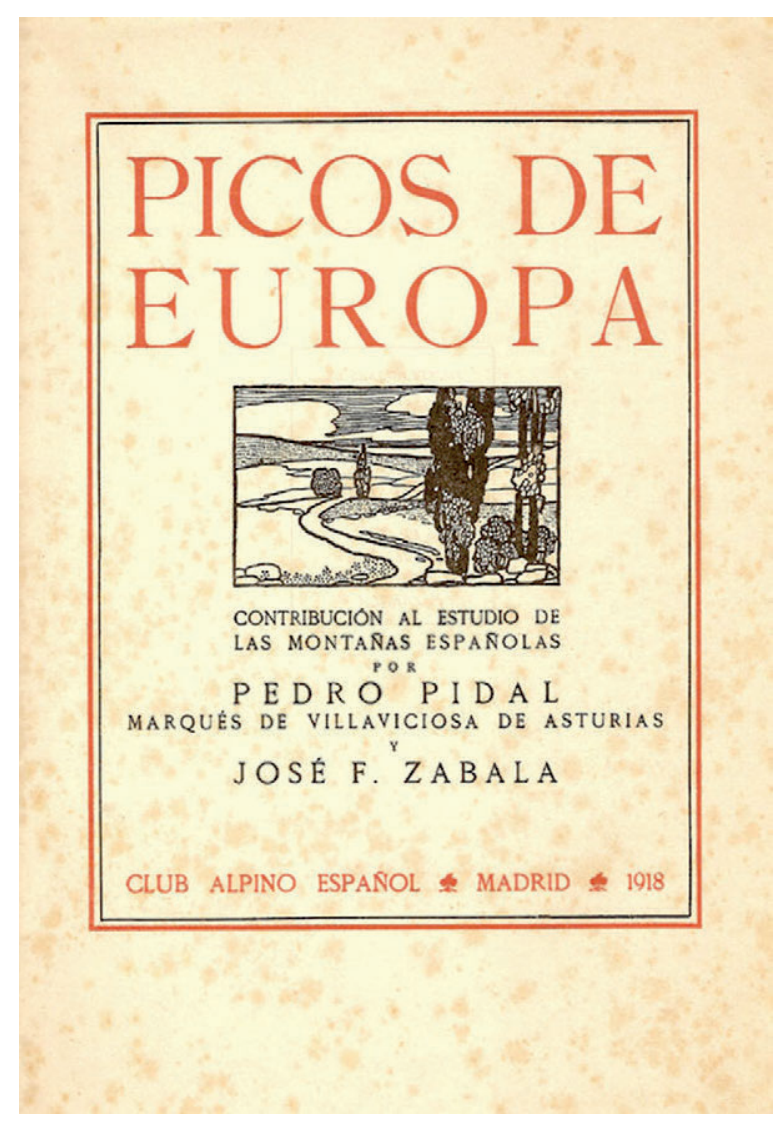

del Villar. Los llamados lagos de Covadonga aparecen también aquí como uno de los paisajes canónicos de los Picos de Europa, en fotografías que combinan la serenidad horizontal de la lámina de agua con lo abrupto de los picachos que invariablemente hacen de fondo (G[onzález] de Amezua, 1929, p. 58, p. 61, pp. 64-65). Los clichés de Antonio Prast, de Santa María del Villar y de otros fotógrafos de montaña, naturaleza y paisaje, como Antonio Victory, se reencuentran igualmente por esos años en los archivos y publicaciones de la Comisaría Regia del Turismo, primera entidad encargada oficialmente de la promoción turística en España (Miguel Arroyo, 2014, pp. 32-35). La Comisaria del Turismo, creada en 1911 con el marqués de la Vega Inclán como "Comisario Regio" y sustituida en 1928 por el Patronato Nacional de Turismo, fue, por cierto, uno de los modelos invocados en 1916 por Pidal para crear los Parques Nacionales (Casado, 2010, p. 260), cuya gestión se encomendó al propio Pidal bajo idéntico título de "Comisario de parques nacionales" (Fernández, 2004, p. 238). 
Figura 3. Reportaje fotográfico sobre los Picos de Europa en el Anuario publicado por el Club Alpino Español en 1929

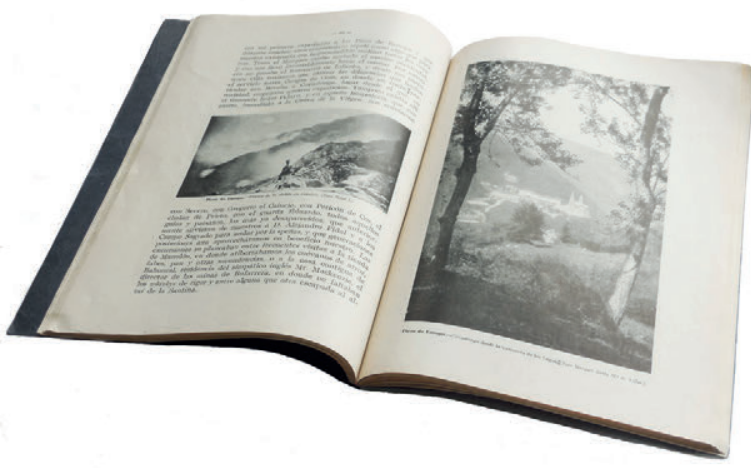

El atractivo que la naturaleza hispana, en estas sus más salvajes y supuestamente genuinas manifestaciones, pudiera desplegar para ofrecer a públicos amplios imágenes con un fuerte componente identitario requería, sin embargo, de canales adicionales a los que ofrecían las publicaciones de alpinismo y montaña, cuya difusión, aunque creciente, resultaba limitada. Una temática conexa y hasta entonces poco desarrollada resultó ser la proporcionada por la fauna, en lo que iba a representar el inicio de una serie de géneros de divulgación zoológica que alcanzarán su apogeo medio siglo más tarde con la singular figura de Félix Rodríguez de la Fuente, de la que se ocupan otros artículos en este mismo volumen.

\section{FAUNA NACIONAL}

La fascinación suscitada en todos los tiempos y culturas por los animales, encuadrada para algunos en una innata "biofilia" (Wilson, 1984), ha encontrado a lo largo del último siglo y medio un nuevo cauce de expresión en las inquietudes conservacionistas. La creación de los primeros Parques y Reservas Naturales, de la cual este ensayo se ocupa, estuvo a menudo ligada al protagonismo de ciertas especies animales particularmente vistosas y admiradas. La paradójica ruta que en diversos países condujo desde una previa cultura cinegética (MacKenzie, 1988), a menudo asociada a prácticas de caza mayor cultivadas por élites aristocráticas en entornos particularmente agrestes, hacia el aparentemente opuesto ideario de la conservación, incluida precisamente la prohibición de la caza, se cumple también en el caso español.

Las iniciativas conservacionistas de Pidal tuvieron su inicial caldo de cultivo en su doble vínculo, por un lado,
Figura 4. Pedro Pidal, cazador de monteses en Gredos

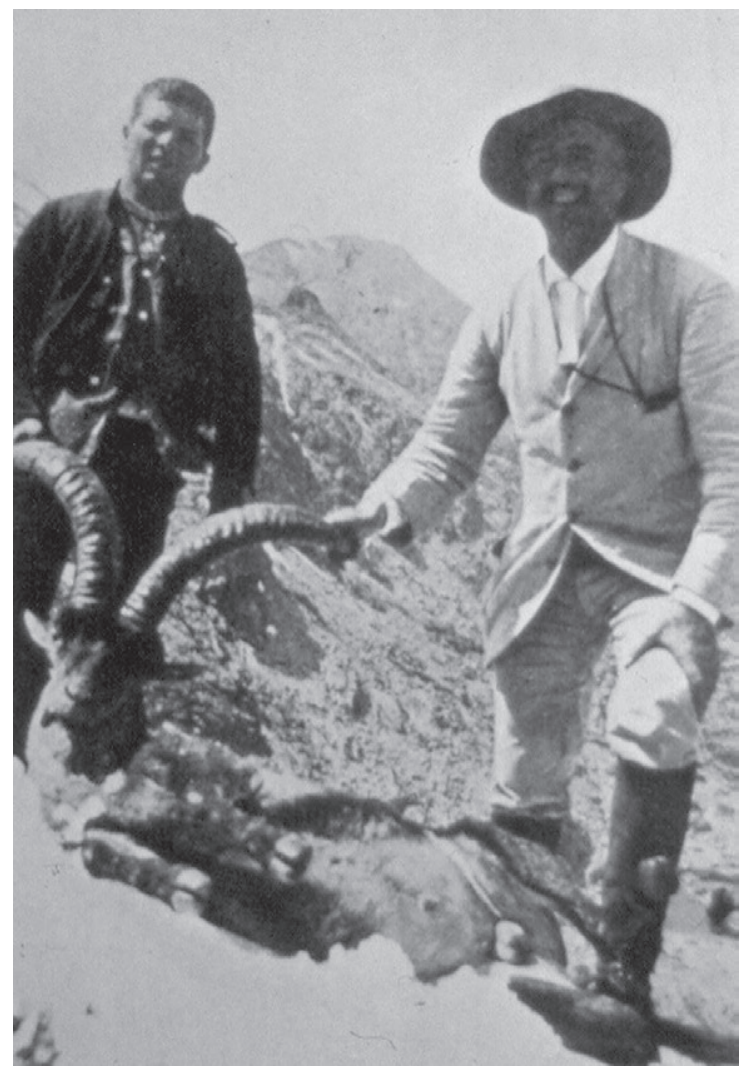

Fuente: Abel Chapman y Walter J. Buck, Unexplored Spain. London: Edward Arnold, 1910.

con la tradición de la caza mayor, heredada de sus mayores y practicada en compañía de patricios y aristócratas, y, por otro lado, con las nuevas prácticas del alpinismo, abrazadas por élites urbanas bajo un signo de neta modernidad cultural. Así, la caza de rebecos entre las escarpadas peñas de los Picos de Europa, e igualmente la de cabras monteses en los riscos no menos desafiantes de la sierra de Gredos, había proporcionado a Pidal y sus compañeros de cacerías, entre ellos el rey Alfonso XIII, la oportunidad de conjugar ambas aficiones. La rarefacción de estas poblaciones de grandes animales montaraces, precisamente por su persecución cinegética, sirvió de estímulo para que a finales del XIX y principios del XX algunos de estos aristocráticos cazadores se convirtieran en conservacionistas.

En el caso de Pidal aparece como episodio clave de su biografía el éxito logrado en su doble iniciativa para proteger las últimas cabras de Gredos y los también amenazados rebecos de los Picos. Éxito conseguido mediante sendas Reservas creadas hacia 1905 con el patrocinio de Alfonso XIII y bajo la figura de Coto 
Real (Casado, 2010, pp. 230-232). Es fácil advertir que se trataba todavía de formas de conservación planteadas en términos cinegéticos, pues su lógica era la de preservar de la extinción poblaciones de animales apreciados como piezas de caza precisamente para poder seguir cazándolos. En estos episodios emerge no obstante una nueva valoración de esa naturaleza a la vez salvaje y amenazada de la que cabras o rebecos forman parte. Una naturaleza que adquiere un sentido propio y autosuficiente, desligado de la instrumentalidad cinegética y asociado en cambio a los valores simbólicos, ideológicos y culturales que se han discutido en los apartados precedentes. Una carta de Pidal a Alfonso XIII, localizada recientemente, recoge con precisión este tránsito entre la vieja y la nueva actitud, que resultará fundamental para la emergencia del conservacionismo.

La misiva, datada el 19 de julio de 1914, poco antes de que Pidal iniciase su campaña en pro de los Parques Nacionales, alude con toda probabilidad a una cacería de monteses celebrada en las montañas de Gredos. Pidal agradece al rey la oportunidad de haber tomado parte en esta emocionante correría, cuya evocación inicia en clave de relato cinegético, sin desviarse aparentemente en nada de las referencias propias del mundo de la caza mayor, incluidas ciertas dosis de exageración y fanfarronería.

"Es el segundo [motivo de agradecimiento] haberme proporcionado V.M. la ocasión de ver entrarnos en un puesto á Pepito y á mi 120 machos: Pepito estaba justo detrás de mí y me largó cuatro tiros por la oreja derecha y otros cuatro por la izquierda... Cobramos uno redondo y otros dos marcharon heridos." Aparece en este momento la nueva componente alpinista, con sus ingredientes de reto físico y de destreza corporal, que Pidal había incorporado a la tradicional experiencia cinegética. "Uno de ellos, de 7 años, fuí á rematarlo al fondo de un abismo realizando una faena alpina arriesgada y primorosa. Isidoro [el guarda] se tiró á cobrarlo por unos acantilados abajo como un bárbaro." Y, entonces, súbitamente, sin previo aviso, el cazador experimenta una mutación inesperada. "Luego, tuve parado delante de mí, inmóvil yo como una peña, á un hermoso macho de unos siete años, y no quise tirarlo." ¿Qué ha ocurrido? ¿Cómo se entiende la renuncia a una pieza valiosa y segura? Pidal se lo explica al rey. "Prefiero verlos Señor con el telescopio, pues es una idealidad contemplar esos animales hermosos sesteando al borde de los precipicios en las aristas de los acantilados." (Carta de Pedro Pidal a Alfonso XIII, 19 de julio de 1914).
La posibilidad de "contemplar" pacíficamente la gran fauna salvaje aparece, al fin, como forma de disfrute alternativa a la previa necesidad de una apropiación cruenta. El "telescopio" de Pidal, que en otro lugar alude a sus "Zeiss prismáticos" en la contemplación de unas "sugestivas gamuzas llamadas rebecos" que "corren y saltan por las peñas velozmente" (Pidal, 1932, p. 7), representa aquí la incorporación de la observación de la fauna, y en particular de especies por uno u otro concepto singulares, como nuevo ingrediente, pronto convertido en imprescindible, del disfrute estético y vivencial de la naturaleza silvestre. Un disfrute que previamente se había centrado, desde sus orígenes románticos, en la experiencia del paisaje y que ahora se va a ver de este modo enriquecido.

Esta incorporación de lo faunístico no es independiente del tipo de consideraciones discutidas más arriba a propósito de las dimensiones nacionalistas del primer conservacionismo. Al promover la creación de los Parques Nacionales Pidal hablará de una "fauna nacional" (Discurso del Sr. Marqués de Villaviciosa de Asturias, p. 356) precisamente para referirse a estas especies, como la cabra montés o el rebeco, en las que se advertían un atractivo estético y un valor simbólico capaces de convertirlas en concentrados emblemas de los territorios cuyos valores se pretendía exaltar y proteger, e incluso de la naturaleza hispana en su conjunto. La nueva valoración de esta "fauna nacional", liberada de su previa servidumbre cinegética, contrastaba sin embargo con la extrema pobreza de los recursos visuales por entonces disponibles para trasladar su atractivo a públicos amplios.

\section{NATURALEZA TRAS EL CRISTAL}

A remediar esta carencia vino un arte que en principio pudiera parecer alejado del signo modernizador que se advierte en todo este proceso de desarrollo del conservacionismo español en el primer tercio del siglo XX. La taxidermia podría, en efecto, asociarse a formas vetustas de exhibición de animales, bien en rancios ambientes aristocráticos vinculados a la práctica cinégetica, bien en los viejos museos de historia natural, concebidos como enciclopédicos almacenes de objetos naturales de toda clase. Pero lo cierto es que en los mejores museos europeos y norteamericanos, ya desde finales del siglo XIX, la taxidermia había ofrecido formas renovadas, a la vez modernas y modernizadoras, para la presentación de ejemplares y grupos animales (Wonders, 1993). Se trataba, por un lado, de plasmar una imagen dinámica y verosímil de los animales disecados, o naturalizados si se prefiere el término utilizado por los 
propios taxidermistas. Gracias a los avances técnicos logrados para entonces por esta disciplina, en la que se mezclan talento artístico, destreza técnica y formación científica, los renovados museos de historia natural podían ofrecer a sus públicos una experiencia mucho más cercana a la contemplación del animal vivo y activo, en las actitudes propias de su modo de existencia en el medio natural. Y, por otro lado, ese modo de existencia podía ser recreado de modo aún mucho más eficaz mediante la combinación de los animales en grupos y en montajes en los que se incluían elementos propios de su entorno, recreando incluso escenas completas mediante la técnica de los dioramas.

En Madrid, el Museo Nacional de Ciencias Naturales, había emprendido, a la altura de 1915 y de acuerdo a las palabras de su Director, Ignacio Bolívar, una "renovación de los ejemplares viejos aislados, formando con ellos grupos naturales, como es práctica hoy muy generalizada en todos o la mayor parte de los Museos" (Bolívar y Urrutia, 1915, pp. 50-51). Grupos naturales, tal como decía Bolívar, o grupos biológicos, como más frecuentemente se los conocía, o también dioramas, según se denominaba a estos montajes cuando incluían efectos escenográficos, tales como fondos con paisajes pintados. Esa era en efecto la tendencia internacional en los mejores museos de historia natural (Poliquin, 2012, pp. 101-107). Y su desarrollo en el Museo de Ciencias madrileño, bajo el liderazgo de Bolívar, vino a coincidir con el despegue del conservacionismo y la creación de los primeros Parques. Así pudo captarse por vez primera la imagen de esa "fauna nacional" y ofrecérsela a un público que, en respuesta al atractivo de esta renovación museística, pronto iba a contarse por decenas de miles de visitantes al año (Casado y Aragón, 2014).

Los artífices de la nueva taxidermia del Museo Nacional de Ciencias Naturales fueron los hermanos José María y Luis Benedito, activos desde 1907 hasta 1955 (Aragón y Casado, 2012). José María, el mayor, se especializó en aves, mientras su hermano Luis se formó en la técnica de la dermoplastia que permitía modelar y preparar mamíferos de mediano o gran tamaño con excelentes resultados (Aragón, 2014, pp. 186-187). Y no es casualidad que el primer grupo biológico creado con esta nueva técnica por los Benedito tuviese como protagonista a los rebecos de los Picos de Europa. El éxito de la iniciativa conservacionista protagonizada por Pidal y el rey Alfonso XIII para proteger estos animales en el Coto Real de los Picos de Europa, y aún más el proyecto de Parque Nacional de Covadonga que por entonces se incubaba, avalaban la elección de esta especie como primera representación de la "fauna nacional" en las renovadas salas del Museo de Ciencias. El proveedor de los ejemplares no fue otro que el mismo Alfonso XIII en su doble y paradójica condición de cazador y conservacionista. Abatidos en una de las cacerías regias en Asturias, las infortunadas bestias fueron donadas por el monarca para servir al cívico y patriótico propósito de educar a sus conciudadanos en las singularidades de la fauna hispana (Casado, 2010, p. 189).

Fue así como hacia 1913 Luis Benedito completó, con la ayuda de su hermano José María, el grupo de los rebecos de los Picos de Europa, con el que se inauguraba toda una serie de espectaculares montajes sobre la fauna ibérica en las salas del Museo Nacional de Ciencias Naturales, donde hasta hoy puede verse (Aragón y Casado, 2012, pp. 44-45). El valor icónico de estas "viñetas de la naturaleza española" (Casado y Aragón, 2014) podía además amplificarse a través de la reproducción de fotografías en toda clase de publicaciones ilustradas. Así, la portada del número del 18 de octubre de 1915 de Alrededor del Mundo, un semanario ilustrado que gozó de amplia difusión en la España del primer tercio del siglo XX, mostraba a toda página el grupo de los rebecos, realzados con una segunda tinta de color, como reclamo para un reportaje en páginas interiores sobre "Taxidermia moderna", acompañado de nuevas fotografías de las obras de los Benedito (Cabrera, 1915, 18 de octubre).

Y, cuando años más tarde se publicó una guía divulgativa y de visita del Parque Nacional de Covadonga, la mejor opción para ilustrar las singularidades de su fauna siguió siendo, a falta de fotografías de calidad de animales en libertad, por entonces aún lejos de las habilidades de los fotógrafos españoles, una imagen del grupo de los rebecos del Museo de Madrid (Delgado Úbeda, 1932, p. 21). El otro gran emblema de la fauna de la cordillera Cantábrica, y del reto que suponía su conservación, era el oso pardo, que aparece también ilustrado en esta publicación mediante idéntico recurso. El correspondiente grabado reproduce una fotografía del ejemplar de oso pardo naturalizado en el Museo de Ciencias Naturales por los hermanos Benedito (Delgado Úbeda, 1932, p. 23). Este ejemplar procedía igualmente de una donación de Alfonso XIII, pero en este caso con la previa intervención del mismo Pedro Pidal, luego creador del Parque Nacional, cuyo rifle había sido el ejecutor del pobre animal, en un lance venatorio que dio lugar a un divertido embrollo (Aragón y Casado, 2012, p. 35).

Peleado con su primo José Bernaldo de Quirós, partícipe en la misma cacería, sobre la autoría de la muerte del soberbio oso que había de representar a la especie en el Museo de Ciencias, Pidal consiguió finalmente que 
Figura 5. El grupo de los rebecos del Museo Nacional de Ciencias Naturales en la portada del número de 18 de octubre de 1915 de la revista ilustrada Alrededor del Mundo

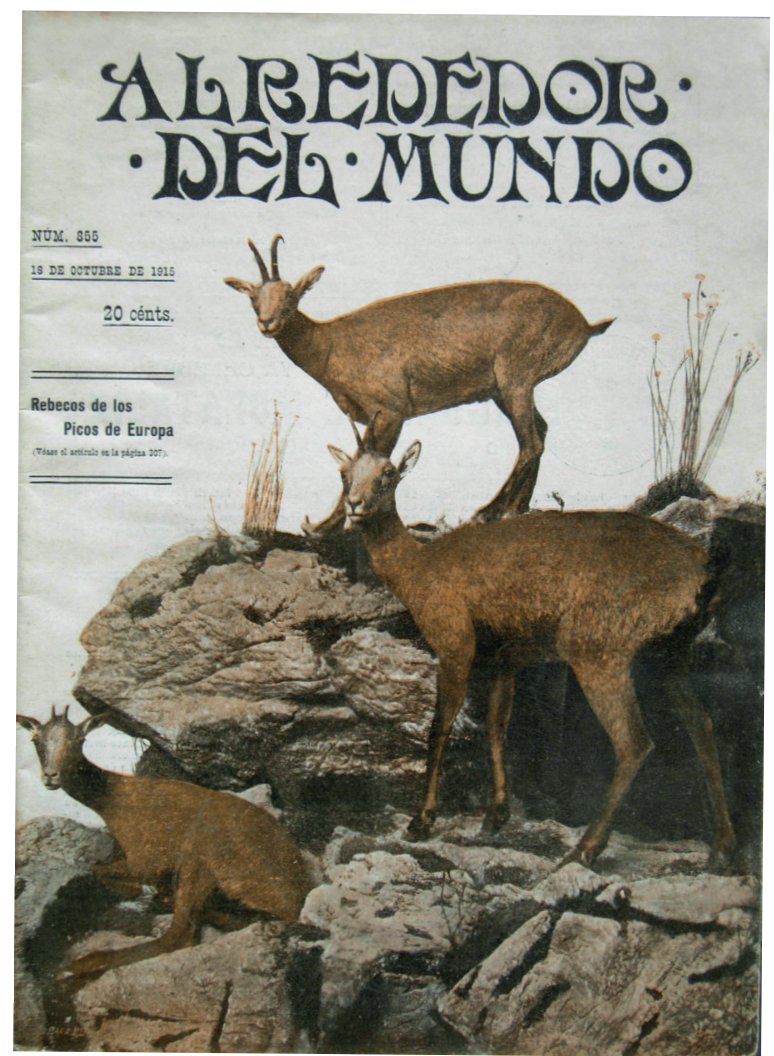

el ejemplar fuera donado al Museo por Alfonso XIII, a quien ambos primos se lo cedieron. En carta al monarca, Pidal argumenta que un "oso regio, el mejor ejemplar de España, que vá al Museo Nacional, se empequeñece, desmerece, si lleva el nombre de particulares; no debe llevar más nombre que el del Rey", de modo que "debe ir al Museo, si V. M. persiste en la idea de regalárselo, con esta sencilla inscripción en placa esmaltada ó perdurable: "Oso muerto en Asturias y regalado al Museo por S. M. el Rey D. Alfonso XIII»" (Carta de Pedro Pidal a Alfonso XIII, sin fecha). Cualquiera que visite el Museo, donde aquel oso habita hasta el día de hoy, podrá leer el rótulo que entonces se colocó y comprobar que el designio de Pidal se cumplió con precisión.

\section{CABRAS HISPÁNICAS}

No solo los rebecos y osos cantábricos se ofrecieron bajo este renovado formato a la también renovada ciudadanía de una España en plena modernización, también las avutardas de las estepas castellanas, los flamencos de Doñana, los abejarucos multicolores, las ceñudas águilas y, por supuesto, los todavía por entonces temidos lobos ibéricos formaron parte de esta galería divulgativa de la fauna española (Aragón y Casado, 2012). Una galería en la que, como puede verse, se anticipaban muchos de los tópicos faunísticos que décadas más tarde iban a recibir un nuevo y poderoso impulso, mediante modelos de conservación específicos, como el caso de Doñana analizado por Lino Camprubí en este mismo volumen, y bajo fórmulas divulgativas muy distintas, en especial de la mano de Félix Rodríguez de la Fuente, también tratado aquí por varios autores.

Pero si había una especie llamada a ser el emblema por antonomasia de esa España auténtica y salvaje, patrióticamente concebida como un primitivo sustrato desde el que insuflar identidad y vigor a una nueva y más moderna ciudadanía, esa era la cabra montés (Casado, 2010, pp. 191-192). A menudo conocida bajo la semicientífica denominación de "Capra hispanica", tan conveniente para el tipo de visiones de la naturaleza patria que aquí se están comentando, la cabra montés de las montañas españolas se diferenciaba, en opinión de los zoólogos, de la especie centroeuropea de los Alpes. Más aún, sus diferentes poblaciones, acantonadas en lo más bravío de distintos macizos ibéricos, a modo de resistentes núcleos de autenticidad primitiva, podían clasificarse científicamente como subespecies distintas, dotadas de una personalidad zoológica propia (Cabrera, 1911). Así, las cabras de Gredos, que en 1905 Pidal y el rey habían salvado de la extinción, se consideraban una subespecie diferenciada dentro de la especie Capra pyrenaica, nombre científicamente aceptado para el conjunto de las cabras ibéricas. Esta subespecie de Gredos recibió en 1911 la denominación científica de Capra pyrenaica victoriae, en dedicatoria a la reina Victoria, esposa de Alfonso XIII, que el zoólogo español Ángel Cabrera consideró oportuno vincular a la descripción de esta nueva forma animal (Casado, 2012).

Tras el celebrado grupo de los rebecos, los Benedito recibieron así de Alfonso XIII las piezas, de nuevo abatidos en cacerías regias, y el encargo para componer un grupo de monteses de Gredos. Un grupo en el que debía encarnarse no solo esa esencia de lo bravío y salvaje de la natura hispana, posible fundamento de virtudes nacionales igualmente concentradas y profundas, sino también la personalidad del propio rey, y de la reina, en su liderazgo de una monarquía renovada y moderna. El encargo, formulado a partir de la donación real de varios ejemplares a lo largo de 1915 y 1916 (Rubio Aragonés, 2001, pp. 72-75), fue cumplido a satisfacción por 
los taxidermistas del Museo de Ciencias, el cual pudo así mostrar en sus salas, como el más acabado de sus montajes, el diorama de las cabras de Gredos, presentado al público madrileño poco después.

La percepción, por parte de sus contemporáneos, de la singularidad tanto del animal como del montaje taxidérmico a él dedicado queda refrendada por el hecho de que Alfonso XIII escogiera esta misma opción, una vez ensayada con éxito en el Museo de Madrid, para dos operaciones de alta diplomacia cultural. La primera y más señalada tuvo como destinatario su colega en funciones monárquicas, y primo de su esposa, el rey Jorge $V$ de Inglaterra, en cuya persona se halló el simbólico destinatario para el regalo que Alfonso XIII hizo al British Museum (Natural History) de Londres. La singular ceremonia de entrega, que tuvo lugar el 7 de julio de 1927, puede reconstruirse a través de la crónica que Luis Bolín, por entonces corresponsal en Londres y más tarde destacada figura política del franquismo, redactó para el $A B C$.

"En el soberbio Museo de Historia Natural de Londres, uno de los mejores del mundo, se ha celebrado hoy el acto, sencillo y simpático, de la presentación por el Rey D. Alfonso al Rey Jorge de un magnífico grupo, constiuído por tres perfectos ejemplares de la rarísisma especie, desconocida en Inglaterra, capra hispánica [sic], procedentes de la zona de Gredos [...] El gran escultor taxidermista Luis Benedito [...] ha labrado el grupo por un habilísimo procedimiento, [...] dando al conjunto un aspecto de naturalidad y realismo extraordinario, que fué muy celebrado por todos los presentes" (Bolín, 1927, 8 de julio).

Tal como también cuida de anotar el corresponsal, la "escultura estaba cubierta por la bandera española", que fue retirada, descubriendo el grupo de cabras al público, en el momento de la entrega, al que evidentemente se quiso dotar de intensidad simbólica. La operación se repitió unos años más tarde con el rey de Suecia y el Museo de Historia Natural de Estocolmo, a donde fue enviado otro castizo grupo de monteses españolas (Aragón, 2014, pp. 213-214).
La alta carga simbólica conferida a los grupos taxidérmicos de fauna española en estos intercambios diplomáticos no viene sino a confirmar la interpretación que sobre su principal papel cultural, que era el desempeñado para con el propio público español, se ha presentado en este ensayo. El más agudo comentario crítico sobre el valor reparador que se quiso otorgar a estos grupos taxidérmicos como sustitutos de una inocente y purificadora naturaleza salvaje, aptos para el consumo cultural de unas masas urbanas amenazadas por las tensiones y el desarraigo de la vida moderna, se halla en el muy citado ensayo de Donna Haraway sobre los dioramas de fauna africana del gran taxidermista norteamericano Carl Akeley.

"La decadencia - la amenaza de la ciudad, la civilización, la máquina-", dice la célebre autora norteamericana, puede ser contrarrestada gracias a "la producción de permanencia" que se ofrece en este peculiar retorno a la natura. Mediante el sucedáneo proporcionado por la experiencia de la fauna en el museo, "la higiene de la naturaleza podía sanar la visión enferma del hombre civilizado". Todo ello tenía que ver con la búsqueda de "preservación, pureza, orden social, salud" (Haraway, 1984-1985, p. 21, p. 25 у р. 57).

El análisis de Haraway se refiere a los montajes taxidérmicos que se reunieron en Nueva York, en el African Hall del American Museum of Natural History, inaugurado en 1936 (Quinn, 2006, p. 18). Para entonces los grupos y dioramas de los Benedito se habían ido convirtiendo también en los protagonistas destacados de su más modesto homólogo madrileño. Pues también en la España del primer tercio del siglo XX se había querido promover un nuevo y vivificante encuentro de la ciudadanía con su naturaleza patria, ya fuera mediante la experiencia física de la visita a los nuevos Parques Nacionales, ya de modo imaginario a través de la propaganda y los relatos vertidos en publicaciones ilustradas, ya bajo las formas vicarias ofrecidas por los grupos de animales disecados que podían exhibirse en las vitrinas de un museo.

\section{NOTAS}

1 Se ha consultado la edición facsímil de Ediciones Noega (Oviedo, 1983). 


\section{BIBLIOGRAFÍA}

Anónimo (1930). La Junta de Parques Nacionales. Peñalara, 194, p. 42

Aragón, S. (2014). En la piel de un animal. El Museo Nacional de Ciencias Naturales y sus colecciones de Taxidermia. Madrid: Consejo Superior de Investigaciones Científicas.

Aragón, S. y Casado, S. (2012). Fauna ibérica en el Museo Nacional de Ciencias Naturales. Los grupos biológicos de los hermanos Benedito. Madrid: Consejo Superior de Investigaciones Científicas.

Barón, J. (2012). El paisajista Martín Rico (1833-1908). Madrid: Museo Nacional del Prado.

Boada, M. (1995). Rafael Puig i Valls, 1845 1920. Precursor de l'educació ambiental $i$ dels espais naturals protegits. Barcelona: Generalitat de Catalunya.

Bolín, L. A. (1927, 8 de julio). Banquete en honor de S. M. el Rey en el Centro Español. Donativo al Museo de Historia Natural. $A B C$, p.23.

Bolívar y Urrutia, I. (1915). Discurso leído ante la Real Academia de Ciencias Exactas, Físicas y Naturales en su recepción pública. Madrid: Real Academia de Ciencias Exactas, Físicas y Naturales.

Boyd, C. P. (2002). The Second Battle of Covadonga. The Politics of Commemoration in Modern Spain. History and Memory, 14, pp. 37-64. http://dx.doi. org/10.1353/ham.2002.0002

Cabrera, A. (1911). The Subspecies of the Spanish Ibex. Proceedings of the Zoological Society of London, 81 (4), pp.963-977. http:// dx.doi.org/10.1111/j.1096-3642.1911. tb01967. $x$

Cabrera, A. (1915, 18 de octubre). Taxidermia moderna. Alrededor del Mundo, 855, pp. 307-309.

Casado, S. (2010). Naturaleza patria. Ciencia y sentimiento de la naturaleza en la España del regeneracionismo. Madrid: Marcial Pons Historia.

Casado, S. (2012). Reinas y cabras. Quercus, 311, p. 12.

Casado, S. y Aragón, S. (2014). Vignettes of Spanish Nature: Imagining a National Fauna at the Museo Nacional de Ciencias Naturales, Madrid (1900-1936). Historical Studies in the Natural Sciences, 44 (3), pp. 197-233. http://dx.doi. org/10.1525/hsns.2014.44.3.197
Casals Costa, V. (1994). El 'bosque urbano': ideología de la naturaleza y proyecto pedagógico en la España finisecular. En: Capel Sáez, H., López Piñero, J. M., Pardo Tomás, J. (coords.). Ciencia e ideología en la ciudad II. Valencia: Generalitat Valenciana, pp. 117-135.

Delgado Úbeda, J. (1932). El Parque Nacional de la Montaña de Covadonga. Madrid: Comisaría de Parques Nacionales.

Esteve, F. (1911). Catálech dels objectes monumentals y arqueológichs. En: Deliberacions del Primer Congrés Excursionista Catalá reunit a Lleyda los dies 25, 25 y 26 de juny del any de 1911 y relació dels actes celebrats en honor dels congresistes. Lleyda: Estampa de Sol y Benet, pp. 249-255.

Fernández, J. (2001). Antología de Textos de la Revista Peñalara. Madrid: Organismo Autónomo Parques Nacionales.

Fernández, J. (2004). Pedro Pidal, marqués de Villaviciosa. En el reino de los rebecos. Oviedo: Nobel.

Findley, R. (1989). The Life and Times of WiIliam Henry Jackson: Photographing the Frontier. National Geographic, 175 (2), pp. 216-251.

Giner de los Ríos, F. (1886). Paisaje. La llustración Artística, 219, pp. 91-92 y La Ilustración Artística, 220, pp. 103-104.

G[onzález] de Amezua, M. (1929). Recuerdos de Asturias. Club Alpino Español. Anuario, 1928-1929, pp. 53-70.

Haraway, D. (1984-1985). Teddy Bear Patriarchy: Taxidermy in the Garden of Eden, New York City, 1908-1936. Social Text, 11, pp. 20-64. http://dx.doi. org/10.2307/466593

Hernández-Pacheco, E. (1920). Comunicación respecto a los Parques nacionales y a los Monumentos naturales de España. Boletín de la Real Sociedad Española de Historia Natural, 20, pp. 267-282.

Kinsey, J. L. (1992). Thomas Moran and the Surveying of the American West. Washington DC: Smithsonian Institution Press.

Lekan, T. M. (2004). Imagining the Nation in Nature. Landscape Preservation and German Identity, 1885-1945. Cambridge, Massachusetts: Harvard University Press.

MacKenzie, J. M. (1988). The Empire of Nature: Hunting, Conservation and
Bristish Imperialism. Manchester: Manchester University Press. http://dx.doi. org/10.1038/331063a0

Martí Henneberg, J. (1994). L'excursionisme científic. Barcelona: Alta Fulla.

Martínez de Pisón, E. (2000). Introducción. En: de España, A. El Parque Nacional del Valle de Ordesa. Madrid: Organismo Autónomo Parques Nacionales, pp. V-XXVII.

Miguel Arroyo, C. (2014). Arte y turismo. De la construcción del mito romántico a la imagen turística de España. En: Visite España. La memoria rescatada. Madrid: Biblioteca Nacional de España y Museo Nacional del Romanticismo, pp. 15-45.

Pidal, P. (1932). Prólogo. En: Delgado Úbeda, J. El Parque Nacional de la Montaña de Covadonga. Madrid: Comisaría de Parques Nacionales, pp. 5-10.

Pidal, P. (1934). El caso de los Parques Nacionales. Gijón: Tipografía La Industria.

Pidal, P. y Zabala, J. F. (1918). Picos de Europa. Contribución al estudio de las montañas españolas. Madrid: Club Alpino Español.

Poliquin, R. (2012). The Breathless Zoo: Taxidermy and the Cultures of Longing. University Park, Pennsylvania: The Pennsylvania State University Press.

Quinn, S. C. (2006). Windows on Nature: The Great Habitat Dioramas of the American Museum of Natural History. New York: Abrams. http://dx.doi. org/10.1038/439546a

Rubio Aragonés, M. J. (2001). Familia Benedito: un siglo de taxidermia y arte en la caza. Badajoz: Ayuntamiento de Badajoz.

Shaffer, M. S. (2001). See America First: Tourism and National Identity, 18801940. Washington DC: Smithsonian Institution Press.

Solé i Massip, J. y Bretón Solo de Zaldívar, V. (1986). El paraiso poseido. La política española de parques naturales (18801935). Geo Crítica, 63, pp. 5-59.

Williams, J. A. (1996). The Chords of the German Soul are Tuned to Nature: The Movement to Preserve the Natural $\mathrm{He}$ imat from the Kaiserreich to the Third Reich. Central European History, 29, pp. 339-384. http://dx.doi.org/10.1017/ s0008938900013674 
Wilson, E. O. (1984). Biophilia. Cambridge, Massachusetts: Harvard University Press.

Wonders, K. (1993). Habitat Dioramas: Illusions of Wilderness in Museums of $\mathrm{Na}$ tural History. Uppsala: Acta Universitatis Upsaliensis.

\section{Textos legales}

Ley sancionada por S. M. creando en España los Parques nacionales. Diario de las Sesiones de Cortes. Congreso de los Diputados, 29 de noviembre de 1916. Apéndice 8 , Núm. 102, p. 1

Ley [de] veintidós de Julio de mil novecientos dieciocho [para la conmemoración del XII Centenario de la Reconquista]. Gaceta de Madrid, 24 julio 1918, p. 227.

Real Decreto [de] dieciséis de Agosto de mil novecientos dieciocho [por el que se crea el Parque Nacional del Valle de Ordesa]. Gaceta de Madrid, 18 agosto 1918, pp. 493-494.

Real Orden [de] 30 de Octubre de 1920 [por la que se declara Sitio Nacional el monte de San Juan de la Peña]. Gaceta de Madrid, 5 de noviembre 1920, p. 606.

\section{Otros documentos}

Carta de Pedro Pidal a Alfonso XIII, 19 de julio de 1914. Archivo General de Palacio,
Madrid, sección reinado de Alfonso XIII, caja 15979/2.

Carta de Pedro Pidal a Alfonso XIII, sin fecha. Archivo General de Palacio, Madrid, sección reinado de Alfonso XIII, caja 15979/2.

Discurso del Sr. Marqués de Villaviciosa de Asturias. Diario de las Sesiones de Cortes. Senado 14 de Junio de 1916, pp. 355-360.

Discurso leído por D. Rafael Puig y Valls, Ingeniero Jefe del distrito forestal de Barcelona, Gerona y Baleares. En Crónica de la Fiesta del Árbol en España, pp. 44-47. Barcelona: Imprenta de la Casa Provincial de Caridad, 1903. 